\title{
El Cosmos y la Hechicería en la Poesía Caldea.
}

\section{UN CAPITULO DE LITERATURA ANTIGUA.}

Entre las altas riberas del Tigris y las márgenes suaves del Eufrates se extiende la llanura bautizada con el nombre de Mesopotamia, donde se cristaliza tal vez si el más antiguo conglomerado humano. Los estudios históricos contemporáneos han penetrado hondamente en las raíces de esa cultura y multitud de teorías se han originado, en el transcurrir del presente siglo, sobre su formación racial, sobre su organización primitiva, sobre el asentarse de las tribus turanias -mestizos procedentesadel Ailtaita,as sumires-tostados, de perfil recioge característicasnsensuales- y muchos otros derivados de la gran familia semítica, sobre el suelo de Mesopotamia

El Eufrates ofrece sus ribazos para la edificación de ciudades: el Tigris, para la construcción de fortalezas. Por encima: un cielo despejado, abierto, cruza un amplio trecho entre las montañas de la Armenia y el Golfo Pérsico, que forma lagunas donde se miran los astros en las noches continuadamente claras del Asia Meridional.

$\mathrm{Y}$ es el cielo el numen, el germen de esa cultura. Si para los egipgios la muerte prende definitivamente en el espíritu y la carrera del sol es una elocuente muestra diaria de 
esa huída persistente hacia el más allá; si para los arios que invaden el Penyab la selva amolda las características de su religión y de su literatura a la fantasmagoría de los bosques, a la majestuosidad del Himalaya, a las corrientes diríamos filosóficas del Ganges y a las tempestades del Mar Indico; si para los hebreos el desierto ha de imprimir, más tarde, la acentuación de lo eterno, la inquietante búsqueda de las fuerzas todopoderosas frente al minúsculo acontecer humano; es inobjetable que el cielo - unas veces terso, otras saturado de estrellas y muchas, envuelto en nubes que forman palacios y fortificaciones entre mensajes de sombra y luz-impresionó definitivamente el carácter mesopotámico. El cielo fué, para ellos, algo concreto, definido. No tuvo un sentido metafísico. Los caldeo-asirios fueron eminentemente materialistas y dieron a sus astros calidades determinadas, influencias precisas. No buscaron jamás un mundo aparte. Todo estaba congregado alrededor de los diosesperfectamente finitos - y del hombre para quien la felicidad estaba de este lado. Una larga vida resumía la aspiración del habitante de Mesopotamia y en ella se cumplía el premio o el castigo. Sobrejlos hombros del campesino cultivador de la vid - para el combate dila lpacanalers del almidonero, la cebada y el trigo, esenciales productos de alimentación; del sésamo y el tamarindo, complementos de los placeres culinarios; estaba Venus-la diosa Isthar- aventurera, heroica, enfermizo y orgiástico motivo de adoración; o JúpiterMarduk-, vencedor del abismo húmedo. Y cuando Ramán -el dios de las tempestades- desata su furia contra las cosechas generosas regadas con las inundaciones del Eufrates, se implora a Anú, que habita en la cúspide de la bóveda ccleste, para que detenga la hora mala. La tradición les ha enseñado que, cuando se desató el diluvio por obra de Enlil, los dioses se acorralaron como perros en lo más alto del cie- 
lo, protegidos por el padre de todas las divinidades, ese viejo Anú, quien los recibió en su palacio maravilloso en "lo más alto" del espacio azul. Pero siempre donde puede llegarse; donde la palabra alto cobra su específico sentido de limitación. Nada se escapa a este maravilloso engranaje de dioses y hombres, ni el Sol justiciero implacable, ni la luna -Sin- de melancolías heróticas, ni Ea, "las aguas que llevan y rodean la tierra". Todo tiene color, todo tiene su parte de cielo y tierra, como un reflejo permanente y sugestivo.

Así, el hombre de Mesopotamia llegó a la ciencia y creó su literatura por un camino perfectamente trazado. La misteriosa influencia de los astros-los designios divinos confundidos con la venganza, la traición y el hechizo-se convirtió, más tarde, en el número y en la cuenta trágica de días y siglos.

Ya dijo Kreglinger en su "Anée Sociologique":

"La Astrología descansa sobre los dos siguientes principios: Roliticlecestrelladoces lascara visible del sagrado mundo oculto cr. $^{\circ}$ existe una relación necesaria entre los fenómenos astronómicos y los hechos de la vida terrestre".

\section{$\mathrm{Y}$ añade Barr:}

"Pero la Astrología ha engendrado la Astrononía, puesto que la idea falsa ha producido observaciones exactas. La ciencia en formación, cuando no sale directamente de la práctica, nace de las especulaciones que orientan el espíritu hacia la Naturaleza".

Dentro de esta predilección por la observación del cielo se orientan, pues, las diversas insinuaciones literarias del 
pueblo caldeo-asirio. En poesía muy suya, dejan los caldeos grabadas sus creencias sobre la formación del mundo, sobre el origen del hombre, sobre los problemas que, transplantados a la Biblia, dan lugar al "Génesis". Con la contribución de sus legisladores sacan, también, de ese mundo especial del encantamiento, del sortilegio, algo que está en la vereda opuesta -podríamos decirlo así- o sea los códigos. Caldea nos ofrece el primer código que se conoce en el proceso humano; a ello la llevó su concepto arraigado de la propiedad privada, las consecuencias de la lucha continua por la propiedad de las tierras, que se originó entre las familias dispersas que fueron acondicionándose en las llanuras de Mesopotamia y que luego pasó a ser contienda imperialista en las manos de los reyes de Nínive o de Babilonia. El Código de Hamurrabi no es en verdad un cuerpo organizado de leyes, sino un resumen total, o una primera consideración general, de la legislación caldea. En un bloque de diorita de $2 \mathrm{~m}, 25 \mathrm{~cm}$. de altura por I $\mathrm{m} .90 \mathrm{~cm}$. de circunferencia, está encerrado lo más disperso de la conciencia jurídica caldea: hechizos y sortilegios, injurias contrâ testiges, robos, disposiciones sobre cultivo; contratos civiles; procedimiento; profesiones; propicdad de esclavos, animales, rural en general, etc. Herencia, partición de bienes, caución y otras figuras, consideradas romanistas, aparecen en esta legislación. Se ha dicho, así, que antes que en Roma se organizó en Mesopotamia una eficiente organización jurídica; y que si en los templos egipcios no se hacía otra cosa que resolver "burocráticamente" el paso a la otra vid'a, en los templos caldeos, y después en los asirios, se hacía justicia con pleno contenido terrenal.

Dentro del sentido imperialista de la vida se formó una literaturạ jurídica, pero también se organizó una literatura guerrera, dirigida a levantar a las multitudes contra los pueblos cercanos. La orienta el espíritu sanguinario de los 
jefes asirios hechos al botín, al saqueo regocijante y "venturoso". Teglatfalsar rinde a la tribu de los mokeos y decapita los cadáveres de los defensores para coronar las murallas ruinosas de sus ciudadies; destruye los palacios, quema los pueblos y se lleva cautivas a las mujeres para las orgías, a los niños para los trabajos del campo. Frente al pacifismo, al amor desmedido por su país, pero que no representa agresión al vecino, que norma el Cuento del Sinué en la literatura egipcia, está este cuadro constante del asalto, destrucción, aniquilamiento de todo lo que no sea perteneciente al grupo, que norma los actos de los reyes de Ashur y que caracteriza a los pueblos imperialistas. Entre la alegría "satánica" del ejército asirio, el águila de Ashurnatsirapla se lleva en sus garras la cabeza de un vencido, dibujando sobre el cielo frases de regocijo por el triunfo e imprecaciones contra los enemigos de Ashur. Y ya son las hazañas de Salmanasar y de Ashurbanipal, ya las de Shamshi-Adad las que llenan las portadas de los templos, las murallas de las ciudades y las piedras dejadas al futuro por los conquistadores. Si el rey caldeo Nabónides relata las fundaciones de las ciudades, los reyes de Ashur, de Ninive, de la segunda Babilonia, nos legan, en sus historian, fastos yellielatos, ell espíritu guerrero, indómito, de estas posteriores etapas mesopotámicas.

Queda, asimismo, de la interesante literatura de caldeaasiria, un sinnúmero de epístolas. La más antigua, encontrada no hace mucho tiempo, es una carta relativa a la invasión elamita de la primitiva Caldea. Se han hallado, también, multitud de cartas del rey Hamurabi, el organizador, dirigidas en particular al gobernador Larsa-Sindinaman; y de Ashurbanipal a sus astrólogos, para curar las enfermedades de sus hijos, asegurar el éxito de sus batallas y obtener una larga vida.

De esta vasta producción nos interesan, principalmente, los dos aspectos que resaltamos a continuación. 


\section{LITERATURA COSMOGONICA.}

Hemos precisado, ante todo, ese estudio, esa inclinación al fenómeno inmediato del cosmo que caracteriza la vida mesopotámica, y que forma el substractum de toda la literatura legada en las reliquias que tan sabiamente han descubierto al mundo las investigaciones de Rawwlinson, de Oppert y otros descifradores de la escritura cuneiforme. Desentranado el misterio de los jeroglíficos de Babilonia, de Susa, etc., y convertidas las tablillas en perfectos libros de divulgación de la cultura de Mesopotamia y la esplendente puerta de Isthar en expresión, no sólo arquitectónica sino literaria, la humanidad ha traído al lenguaje presente los signos caldeos, apreciando una gran cantidad de-leyendas y poemas de singular valor. El paso de las culturas puede estudiarse allí, así como la presentación de motivos literarios que han sido después repetidos o transformados por posteriores estratos culturales de la antigüedad, del medioevo y del presente.

Surge primero un POEMA DE LA CREACION. Hoy se le considera el más extenso poema cosmogónico de Mesopotamia. Las tablillas donde estabà considerado fueron encontradas por Jorge Smith y de su traducción inglesa se ha hecho un arreglo al castellano. Cada tablilla contiene, al parecer, un canto o capítulo, y habiéndose perdido muchas de ellas, el poema está trunco pero conserva toda su fuerza expresiva.

E1 primer canto, consignado en la "Historia de la Literatura" de Pompeyo Gener dice:

"Del tiempo en que, en lo alto, el Cielo estaba innominado $y$, abajo, la tierra no tenía nombre,

el abismo (Apsu) sin límites, fué su generador, y el mar caótico (Mummu-Tiamat) el que creó su conjunto. 
Sus aguas confluían en una;

ningún rebaño de animales se había juntado aún; ninguna planta había brotado.

Del tiempo en que todavía ninguno de los dioses había sido producido, o no estaban designados por un nombre, o ningún desestaba aún fijado. tino

los grandes dioses fueron formadios".

Continúa la enumeración de cada una de las tríadas dentro de esta primera formación universal. $Y$ en la quinta tablilla se hace una presentación perfectamente astronómica.

"Hizo excelentemente las casas en número, para los grandes dioses.

Les atribuye astros y establece fijas las estrellas de la Osa Mayor.

Fija el tiempo del año y determina sus límites.

Para cada uno de los meses fija tres estrellas desde el día en que el año empieza hasta su término.

Determina las casas de los planetas

para definir a un término fijo sus órbitas

de manera que ninguno de ellos pueda faltar,

ni que ninguno se desvíe.

Fija los domicilios de Bel y de Ea, al lado suyo.

Abre también perfectamente las puertas del Cielo

haciendo sólidos cerrojos a derecha e izquierda; y en su majestad fijó grados allí.

En el poema se llama Naunar a la luna, compañera de la noche, que tenía fijada sus fases nocturnas y "para el mes entero sin interrupción” se estableció cuál sería la for- 
ma de su disco. Y añade el poema: "al principio del mes, cuando comienza la noche, tus cuernos te servirán de anuncio para permitirte determinar el tiempo del Cielo".

Delaporte señalando la creencia caldea de que el elemento húmedo había sido el origen de los seres, inserta una primera parte de este poema, en la siguiente forma:

"Cuando arriba el cielo no estaba denominado y abajo la tierra no tenía nombre, del Apsu primordial, su padre, y de la tumultuosa Tiamat, la madre de todos, las aguas se confundian en una.

Los juncales no estaban fijados, las espesuras de cañas no eran vistas, cuando ninguno de los dioses era denominado, cuando ningún destino estaba fijado, los dioses fueron creados".

Hoy se precisa que de allí extrajo Beroso su leyenda de la creación d'el mundo, que también consigna Gener.

"Hubo un tiempoereque todo era tinieblas.... . . . ."

En esta leyendae seuestablececlanprocedencia del hombre dentro del siguiente párrafo:

"Presidía este desorden universal una mujer llamada Omorca. Bel, compadecido de todo, cortola en dos pedazos para establecer el orden. La mitad superior transformose en la Luna y el Cielo estrellado. De la inferior salieron la Tierra vasta y el mar profundo. Bel, entonces, hizo brotar sangre de su propia cabeza, la cual, vertiéndose sobre la tierra, dió origen a los hombres, los cuales, como salidos de la cabeza de Bel, tuvieron inteligencia divina. Luego rasgó las tinieblas y los seres tenebrosos, no pudiendo soportar la luz, se desvanecieron". 
Delaporte considera también dentro del POEMA DE LA CREACION a otra composición que parece, sin embargo, posterior y.que presenta la lucha del bien contra el mal, dentro del combate de Marduk contra la diosa Tiamat, a quien derrota. Este poema nos lleva más allá en la formación del mundo y de los dioses, cuando los engendradores Apsu y Tiamat deciden destruir el universo a instigación de Mummu, surgiendo la figura de Marduk - joven príncipe de los dioses- que salva todo lo creado.

"La madre de la totalidad, la creadora de todas las cosas ha acumulado armas sin igual, ha engendrado enormes serpientes

de dientes agudos, sin elemencia en la matanza, de veneno en vez de sangre hallenado su cuerpo. Ha revestido de espanto a los terribles dragones, de resplandor les ha llenado, les ha dado una grande apariencia.

¡Quien quiera que les vea quedará confundido de espanto! Su cuerpo se endereza, nadie puede rechazar su ataque. "He enviado a Ani, no ha tenido la fuerza de atacarles; Ea se asustó y volvió atrás.

Se ha levantado Marduk, el sabio entre los dioses, vuestro hijo,

a marchar contra Tiamat; su corazón le había impul-

Me dijo la palabra de su boca:

sado.

-Si yo, vuestro vengador,

he de encadenar a Tiamat y haceros vivir.

¡Haced una asamblea, exaltad, proclamad mi destino!-”.

"Tiamat cuando oyó esto quedó de pronto estupefacto y cambió de resolución. 
Miró atentamente lo alto

y fortificó poderosa y completamente su base.

Preparó un sortilegio, colocose........

e hizo tomar las armas a los dioses que combatían con

ella,

y Tiamat asaltó al heraldo de los dioses, Marduk;

se precipitaron ardientemente el uno sobre el otro en el

y trabaron batalla.

combate

El señor sacó su cimatarra e hiriole;

lanzó ante él, el viento maligno que sopló detrás de ella. Y Tiamat abrió la boca para tragarlo, pero el señor hizo entrar el viento en su boca

de tal modo que no pudo cerrarla.

$\mathrm{La}$ violencia del viento llenó su vientre;

desfalleció su corazón y se torció su boca.

Marduk echó adelante su arma poderosa y rompió su

la dividió por en medio y hendió su corazón;

vientre,

la derribó y extinguió su vida".

De singular animación es el POEMA DEL ORDEN DE LOS MOVIMIENTOS Y DE LA LUCHA DE LOS SIETE ESPIRITUS MALIGNOS CONTRA EL DIOS LUNA. Es éste el canto triunfal a Sin, a quien ayuda también Mardurk en una lucha santa contra los siete grandes enemigos que "como torbellinos desvastan la vida en la superficie de la tierra". Estas fuerzas malignas se interpusieron entre la luna y nuestro planeta, y se aprecia, entonces, la preparación del combate, el relucir de las armas divinas. El triunfo acompaña a las fuerzas del bien, a las supremas influencias celestes, pero la pelea ha de renovarse eternamente dentro de esas tendencias contrarias que gobiernan el universo. Esto, hay que señalarlo, no es propiamente la peren- 
ne contienda entre Ormuz y Ahrimán que conciben los persas. En Caldea se plantea, en particular, la observación, la entusiasta adoración por los movimientos, revoluciones y fenómenos estelares. El poema, que indicamos, es un estudio de astronomía en cauce; y se completa, por supuesto, con imperiosas predicciones de orden astrológico.

"Los dioses del cielo y de la tierra reducirán los hombres a polvo y causarán su ruina; habrá eclipse, innundaciones, enfermedades, mortandad. Los siete grandes espíritus malignos opondrán obstáculos a la Luna”.

Otra vez volverá, luego, la vida a florecer con un nuevo triunfo de Sin. Destrucción y construcción responden a una concepción materialista acentuada.

Uta-naphistin - Noé babilónico le llama Delaporte- es el héroe del POEMA DEL DILUVIO, antecedente irref1table de la relación bíblica. Como el patriarca hebreo, el "padre" de la raza caldea carga su barco con "toda simiente de vida", cuando el Sol le anuncia la catástrofe que se aproxima. Poco después comienza el diluxio.

"El hermano "Jorge Puccinellicrno ve a su hermano,

ya no se reconoce la gente en los cielos.

Los dioses terminaron el diluvio, huyeron y subieron al cielo de Anú.

Los dioses se acurrucan como el perro;

sobre la muralla están acostados.

Seis días y seis noches dura para Uta-naphistin ese torrente de agua; y al cabo de ellos dice el relato:

"Miré al mar, la voz había callado

y toda la humanidad estaba convertida en fango.

¡Hasta“los tejados llegaba el pantano.

Abrí la ventana y el día cayó sobre mi mejilla. 
El Poema de Gilgamesh, como se le ha llamado es la más bella pieza literaria de la tradición mesopotámica. Se nota su influencia en la posterior - y más desarrollada- literatura israelita. Sólo que la prosaica concepción de los dioses caldeos lleva a éstos, al final del poema, a la ofrenda que sobre la montaña de Nitsir dedica Uta-naphistin.

"Los dioses husmearon el olor.

Los dioses husmearon el buen olor.

Los dioses como moscas se juntaron

sobre el sacrificador.

LA TORRE DE LAS LENGUAS se bautiza al otro poema que también ha servido de antecedente a la Biblia y que seguramente llevó en su peregrinación por Arabia, Egipto y Palestina, el grupo mesopotámico que partió de Ur. De la tradición surge la-ciudad de Bab-ilou que los primitivos habitantes gigantes construyeron esforzadamente y donde levantaron una torre con la que pensaban llegar a la morada de Anú. Los yientos auxiliaron a los dioses y dejaron en escombros la citdad, castigando a los hombres con la diversidad de lenguas que hablafon, desderentonces, al alejarse por múltiples caminos de la región babilónica.

La leyenda ha pretendido perennizar la idea arraigada en el mundo antiguo de que en Mesopotamia se encontraba el "nido humano"; y que por lo tanto de la llanura del Eufrates y del Tigris salió la humanidad para poblar las demás regiones que se perdían más allá del Nilo, más allá del Ganges.

\section{IITERATURA DE LA SUPERSTICION.}

Ya hemos visto como los caldeos y asirios se acostumbraron a sus dioses mezquinos, que pelean por la comida de 
los hombres, que gozan con el espectáculo de las carnicerías humanas, de las cabezas colgadas en las murallas de las ciudades. Dentro de ese "ambiente" concebían que todos los males procedian de sus dioses inferiores, de los que estaban en el plano intermedio entre los grandes dioses, a quienes se suplicaba protección a trueque de beneficios perfectamente materiales, y los hombres. Sólo el influjo de los poderosos podía hacer desaparecer las causas del mal. Por otra parte, lanzada una imprecación, los dioses pequeños se ponían en acecho del señalado y concluían por enviarle las desgracias que se había requerido para él. Nacía la hechicería dentro de las mismas direcciones astrológicas. EI paso de las estrellas, los aspctos que presentaba el cielo inflúán decididamente sobre la vida de los hombres y se requería que los conjuradores o los sacerdotes consiguieran la buena influencia de los astros o aprovecharan, más bien, su aceín en contra de determinadas personas. El destino-que era marcado por las estrellas y que se reflejaba en los ojos del predestinado, en sus sueños y alucinaciones-podía seren parte cambiado por la eficaz intervención de los espíritus superiores que ejercían el sacerdocio. Puede parecer quet toda esto es comủn a las concepciones primarias de đosepueblośnehliformación," pero en Caldea y Asiria orientó todos los caminos de su vida, dejando impresa una consigna al lado de las manifestaciones superiores de su elevación cultural en el orden de la ciencia y de la propia literatura, donde se crea una poesía del hechizo. El mundo de la ilusión y del encantamiento toma forma literaria y se concibe en realidad toda la belleza de la palabra: magia. Arriba el cielo preside la marcha de una humanidad sensual. Los emperadores, estremecidos de terror, ven acercarse sil fin o, embelesados, reciben el mensaje de sus futuros triunfos. En los banquetes orgiásticos, la diosa Isthar anuncia sus caprichosas órdenes celestes, y en medio del regocijo de Bal- 
tasar, las palabras "Mane, Thecel, Fares" rubrican en tragedia la marcha triunfal de Babilonia.

Si todos los pueblos de Oriente dejan aportes a la literatura de la hechicería, en Mesopotamia ésta es un perfecto derrotero y se basa -o pretende basarse-en explicaciones causales que los astrólogos conocen y los poemas difunden.

La fórmula del encantamiento caldeo es una letanía que se repite dentro de un sonsón cadencioso:

“ ¿Espíritu del Cielo, acuérdate! ¡Espíritu de la Tierra, acuérdate!

¡Espíritu de Mulge, rey de las comarcas, acuérdate!

¡ Espíritu de Ningelal, señora de las comarcas, acuérdate!

¡Espíritu de Nindar, hijo del cénit, acuérdate!

¡Espíritu de Tiskhu, señora de las comarcas, que brillas en las noches, acuérdate!

A veces ese ritmo sirve para recalcar, en lenta enumeración, los posibles factores de desgracia:

"La noghe de makiaugurio la región del cielo que produce la desgracia; el día funesto, la región del cielo maligna a la observación; el día funesto, la región del cielo maligna, que avanza...; mensajeros de la peste; desvastadores d'e Ninkigal; el rayo que arrasa el país; los siete dioses del vasto Cielo; los siete dioses de la vastá Tierra; los siete dioses de las esferas igneas; los siete dioses de las legiones celestes; los siete dioses malhechores; los siete fantasmas de llama maligna; los siete dioses del Cielo; los siete dioses de la Tierra; los demonios malignos, el alal maligno, el gimgim maligno, el telal maligno, el dios maligno, el maskim maligno". 
E1 número siete predomina en todas estas acechanzas de los conjuradores. Sinfonía en siete es también la fórmula de hechicería siguiente:

Los Siete, los Siete, en lo más profundo del abismo, los Siete, abominación del Cielo, los Siete, escondiéndose en lo más profundo del abismo

y en las entrañas de la Tierra, ni machos ni hembras, sin esposa ni hijos, sin conocer el orden ni el bien, sin escuchar las plegarias, gusanos que se esconden en la montaña, enemigos del dios Ea, desvastadores de los dioses, autores de disturbios, soberbios por la violencia, agentes de querellas, agentes de enemistad".

$Y$ continuando en este camino dramático, en este "in crescendo" de maldiciones 0 augurios, existe una fórmula que suma todas las posibles calamidades que deban desatarse contra el "señalado" por la conjuración. La recoge Pompeyo Gener, y comienzal así:oteca de Letras

"A este hombre las imprecaciones le precipiten en las aguas; ellas lo arrastren al fondo; lo destrocen contra las piedras; lo quemen por el fuego; lo lancen al destierro en lugares dionde no se pueda vivir. ¿Que Anú, Bel, Nuah y la señora suprema (Belit) y los grandes dioses le cubran de una confusión absoluta; que desarraiguen su estabilidad; que borren su posteridad!".

Se continúa en ese mismo tono hasta terminar en la siguiente frase:

"iY que todos los grandies dioses, cuyos nombres quedan mencionados en esta inscripción, le naldigan con 
una maldición que no pueda ser retirada y que dispersen su raza hasta el fín de los días!".

Fórmulas como ésta mandan inscribir los reyes y los altos jefes en defensa de las leyes dadas, de los monumentos eregidos o en contra de los traidores y de los enemigos de Caldea o de Asiria.

La labor del médico hechicero se concretaba a anular esos males. A ellos se dirige la multitud en son de remedio, de protección. Los grandes sacerdotes, en medio del ceremonial que consignan los historiadores, imploran de los altos dioses su decisiva influencia.

"Silik-mulu-khi lo ha socorrido; hacia su padre. Ea, en la mansión ha penetrado y le ha dicho: Pad're mío, la imprecación es para el hombre como un demonio del infierno. A propósito del mal le dice: Combina el número; ese hombre no lo sabe; está sometido al número. Y Ea, a su hijo Silik-mulu-khi responde así: Hijo mío, tu no conoces el número, yo te dispondré el número; Silikmulu-khi tu nolconocesal cuumero; yoste enseñaré el número; lo que yo sélo sabes itú oye, hijo mío Silik-mulukhi.... elevado; preséntale una mano favorable; expón el orden del destino, manifiesta el orden del destino".

"Mal, sal de su cuerpo, aunque seas una imprecación de su padre, una imprecación de su madre, una imprecación de su hermano mayor, una imprecación de un hombre desconocido".

Las tablillas conteniendo estas fórmulas de hechicería médica hạn servido, así, entre otras cosas, para el estudio de enfermedades posiblemente originarias de la zona caldeaasiria. Pero lo que directamente nos interesa es la formación, 
en gran escala, de esta clase literaria de la maldición, el encantamiento, la conjura. La maldición de los Emperadores y sacerdotes; el encantamiento en manos de los sabios astrólogos; la conjura de los médicos sacerdotes. Un ritmo especial caracteriza a todos esos poemas. Es el ritmo que apt11ta repetidas veces en la Biblia, que forma las letanías de la primera etapa literaria hebrea, cuando se concibe el Poema de Job - cuyo antecedente es el POEMA DEL JUSTO en Caldea - y cuando aún el dístico no había alcanzado la soltura del Cantar de los Cantares.

Curioso es hallar un nexo entre esa literatura y la aparición de una poesía negra, con sabor hebraico, en América. Gracias a la Biblia de los catequistas el negro americano ha cogido algo del ritmo semita y lo ha asimilado al erótico sentimiento africano. Ha dicho Ildefonso Pereda Valdés:

"I La Biblia anda metida en los cantos de los negros que han visto en el libro de los libros la magna obra de su raza (?). La interpretaron a su manera, como a todas las ceremonias de la vida".

Se ha afirmado, asi, con autorizada palabra la influencia hebrea en el canto negro americano. Pero debe precisarse que prima en ellos la letanía de las fórmulas de hechicería caldea, que heredaron los israclitas.

"Buenas noticias, buenas noticias, sacristán.

Hay un largo camino que yo conozco.

Buenas noticias, sacristán.

Hay una corona estrellada en el cielo que yo conozco.

Buenas noticias, buenas noticias, sacristán.

Hay un arpa de oro en el cielo que yo conozco. Buenås noticias, buenas noticias, sacristán, 
Dice una canción de los negros de Estados Unidos. Regino Pedroso, el original poeta de Cuba, tiene una poesía que comienza así:

\author{
"Negro, hermano negro, \\ tu estás en mí: ¡habla! \\ Negro, hermano negro, \\ yo estoy en ti: ; canta! \\ Tu voz está en mi voz, \\ tu angustia está en mi voz, \\ tu sangre está en mi voz, \\ ¡También yo soy tu raza! \\ Negro, hermano negro, \\ el más fuerté, el más triste, \\ el más lleno de cantos y lágrimas. \\ Y Nicolás Guillên expresa: \\ "Sigue, no te pare, \\ sigue; \\ Froblei mirecsi te dlamatras

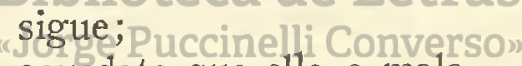 \\ acuedate que ella e mala \\ sigue".........
}

Es éste un posible filón de estudio, de persecución de temas literarios, que puede dar motivo a un análisis de las sucesivas influencias que van de Caldea a Palestina-marcha de una raza en camino de espiritualidad-y de Palestina a los núcleos negros de nuestro Continente-extraña filtración a través de muchas culturas-y que tiene singular interés para la historia literaria.

Augusto Tamayo Vargas. 